\title{
CROSSING CULTURES AND BORDERS IN INTERNATIONAL ONLINE DISTANCE HIGHER EDUCATION
}

\author{
Gulnara Sadykova \\ University at Albany \\ Jennie Dautermann \\ SUNY Center for Professional Development in Syracuse
}

\begin{abstract}
The growing demand for higher education worldwide, along with global expansion of telecommunication technologies, give online distance education a potential world-wide reach for institutions in many countries. Given the persistent international digital divide and the potential for the host institutions and languages to be those of wealthy, industrialized countries, international online distance higher education (IODHE) has great potential for educational and cultural imperialism. Therefore institutions contemplating expansion into international distance education must accommodate a number of changes that would enable building the safe learning/teaching environment needed for development of a successful course. Drawing on literature of domestic and international online teaching and learning, multicultural studies, as well as personal international teaching and learning experience, the authors examine four domains where these changes are of critical importance: 1) host institution, 2) technology, 3) learning models of students, and 4) teaching models of faculty. The paper discusses issues and practices in each of these domains and offers general recommendations for institutions participating or planning to participate in cross-border/cross-culture online education.
\end{abstract}

\section{KEYWORDS}

Distance Education, Online Education, International Students, Higher Education, Culture, Cultural Differences, Institutional Policies, Educational Technology, Teachers’ Beliefs, Students’ Expectations.

\section{INTRODUCTION}

The growing demand for higher education worldwide, along with global expansion of telecommunication technologies, have given online distance education a potential world-wide reach for institutions in many countries [1, 2]. Those responsible for the financial health of institutions often look to emerging international markets as an opportunity for growth in spite of geographical or demographic limitations on their current enrollments. Consequently van der Wender reminds us that "The process of globalisation, characterized by increasing global economic interdependence and international competition, leads to the emergence of an international higher education market in which a growing number of traditional and new types of higher education providers compete with each other" [3, p.2].

Institutions contemplating expansion into international distance education must accommodate a number of changes. For example, policies initially designed to meet the needs of the "residential" university that present obstacles to distant online students, complexities of computer mediated instruction and technology mismatches, and perhaps most significant for the individual students and faculty, different 
assumptions about teaching and learning that must be addressed in subtle and complex ways in the virtual international classroom are of critical importance. This paper explores some of these accommodations.

For our current purposes, we assume open courses that bring together students and faculty from a variety of cultures and geographical locations. We refer occasionally to partnership models that work between two or more specific cultures, but in general we are positing virtual classrooms where a common language is shared, although not with equal fluency, where students may represent a number of nationalities or cultures, and where the instructor may bring in yet another nationality or cultural heritage. We anticipate that such variety will eventually be the norm for international online distance higher education (hereafter referred to as IODHE) in the future, although many more limited experiments are underway at this time due to cross national partnerships, language issues, and differences in technology access [4].

Our reading for this paper has focused on the literature of international online teaching and learning as well as some collateral work on international students studying in residential settings and on the literature of multicultural teaching and learning. Our discussion is informed as well by our own international teaching and learning experiences and a belief that education and cultures are highly interdependent. We also believe that given the persistent international digital divide and the potential for host institutions and languages to be those of wealthy, industrialized countries, IDOHE has great potential for educational and cultural imperialism [5, 6]. Furthermore, the pressure of competition from for-profit schools may also contribute to a climate where there is more focus on building income than on nurturing students. Our discussion attempts to account for these complexities and to offer strategies for a more equitable vision of shared resources via the growing, though certainly not universal, access to the world wide web across the planet.

The diagram below lays out the four domains of IDOHE as a square in which each domain is shown to have connections to all the other three (Figure 1). The assumptions and functions of each of the four domains vary across cultures, across the previous educational experiences of students and faculty in a particular course, and across disciplines and types of institutions. We refer to these four dimensions as "discourses" because of the primacy of language (and other symbols) in making these domains visible in online environments, and because of the persistent need for negotiation to resolve inevitable conflicts within the temporary international community generated in any individual course. Each "discourse" in our diagram represents practices that may be culturally transparent to the host culture but which may seem particularly ethnocentric when viewed from an IDOHE perspective.

The illustration represents an individual IODHE course along with its supporting infrastructure. The inner square with its interconnected sides represents the discourses that inform and constrain the work of the students and instructor in that course. Besides its disciplinary content, any successful IDOHE course must be supported by a consistent effort across these domains as illustrated by the connecting lines. Thus IDOHE technologies must account for faculty and student needs, and be supported by an institutional discourse that acknowledges this relationship. We will first turn briefly to the assumptions and practices of institutions and technologies of concern to an IODHE course. 


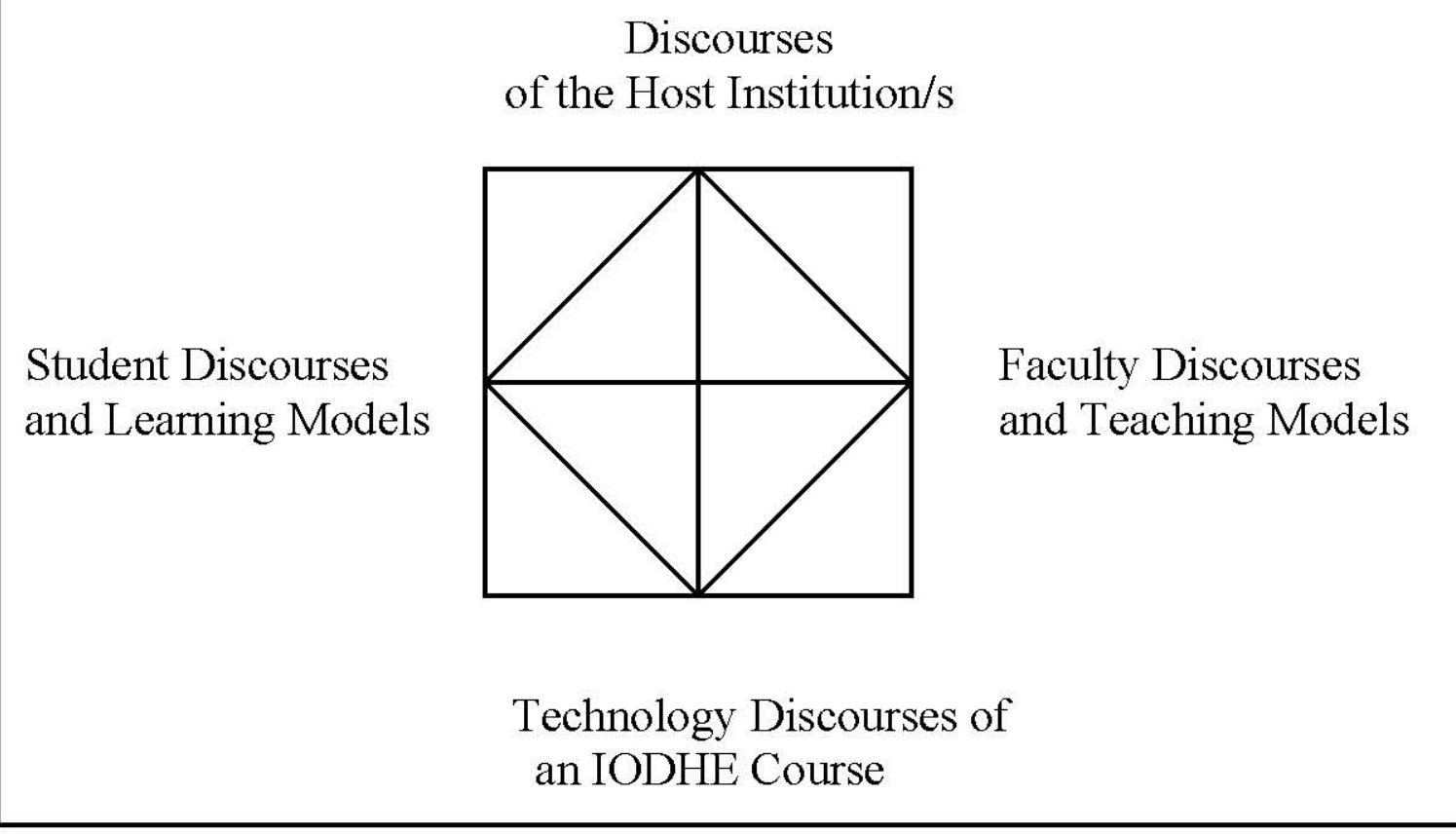

Figure 1. Discourse Domains of an IODHE Course

\section{DISCOURSES OF THE HOST INSTITUTION/S}

Putting institutional discourses at the top of our diagram acknowledges that institutional language and policies are a significant context in which IODHE is embedded. Darrup-Boychuk [7] and Sedgewick [8] remind us that individual institutions as well as national and provincial educational bodies and systems of accreditation have the power to foster IODHE and may have concrete economic or social reasons for doing so. Harley et al. [9] and Australia' Competitors [10] suggest that national governments with their control over immigration and trade also generate policies that may directly or inadvertently create barriers to IODHE planning and student recruitment. We acknowledge these issues as significant to the success of any individual IODHE effort, but for the purposes of this paper we shall confine our discussion to the institutional policies and practices of the host institution that directly affect IODHE work inside classrooms. Some of these practices derive from assumptions about the residential nature of an institution and lie deeply embedded in such mundane matters as student recruitment and enrollment, the academic calendar, requirements for earning credit, and preparation of faculty.

\section{A. Institutional Issues for IODHE}

Since the institutional impetus to build IODHE programs reflects, in many cases, a goal of increasing enrollment and income for the host institution, such projects tend to assume that the host institution has both the content and the delivery of knowledge in hand, and that with the addition of technological support, and perhaps some marketing and brand management, international online teaching projects only require minimum planning for instructional adaptations. Care must be taken to insure that such a colonialist model does not inform this planning, as Adam implies when he says, "Transnational education is the educational manifestation of this globalization process and strategies to adjust to it must fit with other national educational goals, e.g. to promote lifelong learning, transmit culture and increase competitiveness, etc" [11, p.49]. 
Certainly many institutions interested in IODHE have been hosting international students on their campuses for years without much adaptation of the courses to their presence. Often international student services, TA arrangements, and immigration questions are dealt with in offices of international studies where specialized staff members intercede with institutional policy matters with individual students.

When international instruction is moved into a virtual space, however, many student adjustment issues dealt with by international studies offices (visa applications, housing, adjustments to a new culture) become somewhat less urgent on campus. At the same time, adaptation of the actual classroom practices to the international online students' needs may be moved into other institutional offices where policies have not previously accounted for international students. Some institutional policies, for instance, assume that all enrolled students can visit campus offices to pay their bills, sign forms, be advised, sit for ID pictures, and more. And while a few campuses are well on the way to moving student services for registration, paying fees, and advising into virtual spaces, many other schools do not make this shift a priority even though they are actively promoting online distance enrollments. This mismatch may not be evident in initial online projects for commuting students who live reasonably close to campus, but in the process of offering a course to a worldwide audience, these policies may bring certain issues into greater prominence. Since such policies sit in a quite different institutional location from traditional international student services, accommodation to IODHE may require an institutional commitment that extends well beyond the distance education office. Robert Knipe claims that policies designed for residential students are a significant factor inhibiting the growth of online programs at his own institution [12]. He cites examples in which his online students have been unable to register, pay tuition bills, secure library privileges and meet specific graduation requirements because of policies that require them to be physically present on campus.

Other campus policies may not require students to be on campus, but may make it difficult for a course to be offered online in parallel with similar courses offered on the campus. Prerequisites, random assignment of students to multi-section courses, and attendance policies designed for residential settings may interfere with the offering of specific courses online. Scheduling of IODHE courses can be incompatible with the host institution's rules about drop/adds, or number of contact hours, or efforts at modest synchronous activity across world-wide time zones. Even catalog labeling of online sections becomes significant for IODHE students, and may be subject to elaborate institutional approval processes.

Policies that are applied to all students on a campus regardless of full time or part time status can also present difficulties to distant online students. The State of New York, for instance, has a requirement that any student in its universities and colleges must show proof of immunization against certain diseases particularly prevalent in college age populations. Other systems have mandatory health insurance fees for students who register. Program directors in New York were able to get the immunization requirement waived only for students who never set foot on the campus under any circumstances. The institutional discourse of a residential campus that underlies many of these examples may depend on long held assumptions about campus life and may require careful negotiation of traditional institutional practices.

Finally, marketing and recruiting students can look quite different in an international setting when compared with an institution's local efforts. New legal issues are likely to arise for IODHE courses: legitimacy of certain fees, negotiations with international sites for proctored exams, and developing of partnerships for distant support for hybrid efforts or laboratory experience are added to the institution's responsibilities. Indeed Sedgwick [13] predicts that this need for services may introduce a significant amount of risk for IODHE students who must depend on an institution's public discourse to determine whether there are adequate resources for them on a particular campus. See also [2]. 


\section{B. Institutional Practices that Open Up Spaces for IODHE Courses}

Some traditional institutions have addressed IDOHE issues described above by moving online instruction into some non-traditional space for campus services such as continuing education where students can be served by different policies than those designed for residential students. This move illustrates the first stages of a mindset change that is required for an institution that would open its "residential" campus doors to students who represent neither residential nor commuting student groups. This mindset change would involve thinking of the campus as a much more open (even global) physical space. Other strategies for opening up an institution's campus come in many forms, some of which seem to be small steps on the way to something more global.

\section{Choosing an Appropriate Program Design and Delivery Model}

One way to reduce the complexity of international online distance education is to limit program design and delivery models. Several studies have discussed institutional partnerships where only two institutions and fewer language groups are represented. This strategy serves to reduce the scope of the multicultural mix in early efforts $[14,15]$.

Hybrid courses that combine face to face meetings with online work, often useful with working or disabled students $[16,17,18]$ ) can sometimes be replicated with middle-ground IODHE strategies that mix online with face to face instruction in different ways. Tutors and satellite classrooms can sometimes be offered at some distance from the campus centers and connected by lectures broadcast over great distances [19]. Wiesenberg \& Stacey recommend blended pedagogies that combine more traditional didactic methods with collaborative strategies [20]. We expect mixed-mode programs where students live one year in the host country taking residential classes and then complete their degree studying from home online to emerge eventually.

Labour and his colleagues [21] point to courses that are taught in multi-lingual modes, and Branden \& Lambert [22] also argue for a multilingual approach. Other solutions involve offering options in the length of the course to accommodate different calendars. Washington State University, for instance, offers flexible enrollment courses where students can take an additional semester to complete course work for a $\$ 100$ fee [23].

\section{Matching the Course to the Student}

Educational institutions need to share the responsibility of matching course expectations and requirements to student's needs and abilities. Bentley, Tinney \& Chia [5] suggest that institutions prepare for IODHE projects by looking carefully at course catalogs, and registration and recruitment materials. Early information about course requirements, learning resources and expected outcomes are seen by Troy State University, Montgomery as essential for students to make wise choices [24]. Washington State University accompanies some course syllabuses with RealPlayer videos introducing the instructor and describing the course objectives [25].

At Western Governors University new online students complete a skill survey and are assigned mentors who conduct extended phone interviews for academic planning [26]. Proactive academic advising is also offered at Saint Joseph's College of Maine, where advisors keep regular contact with prospective distance students via phone, mail, and email [27].

\section{Academic Support}


Ongoing 24/7 academic support remains a dream for many active distance students. Still some institutions establish support systems that are accessible throughout most of the week. Mentors at Western Governors University are reported to provide feedback within 24-48 hours; besides electronic communication, they make themselves available for phone appointments [26].

Electronic communication with peer mentors is often attractive for IODHE students. Distance students at Berkeley College and Mercy College have already had a chance to see advantages of faculty and peer tutors in all subject areas including specific writing for papers or essays. Mercy College students feel more at ease with assistance from other students or online "wizards" who serve as tutors, facilitators and role models [28]. To improve foreign language speakers' academic writing skills, Capella University offers a course Graduate Writing for ESL/EFL Learners [29].

Some educational institutions offer preparation courses and custom tutorials to help new students fill knowledge gaps. Berkeley College, Stanford, SUNY Empire State College, and the U.S. military have all developed self-tests or preparation courses for online students [30, 31, 32].

\section{Preparing Faculty}

Professional development courses with emphasis on cross-cultural issues is essential for faculty who participate in IODHE. Maryland Online's highly regarded online training for new faculty offers learning modules related to the design and management of online courses [33]. At Florida Community College at Jacksonville new adjunct online faculty are assigned virtual mentors who advise on pedagogical, logistic and technology matters [34]. Comprehensive faculty support provided by the State University of New York's SUNY Learning Network (SLN) assists both new and returning faculty in designing, facilitating, evaluating and re-designing online courses [35].

Labour, Juwah, White, \& Tolley [21] describe an online workshop originally developed under the Online Tutoring Skill Project to prepare staff in Scottish higher education institutions. The workshop agenda addresses many challenges an online instructor may encounter in a multicultural classroom and provides suggestions to help avoid cultural misunderstanding in an online learning environment. Training 'global' e-teachers, knowledgeable in pedagogies and prepared to work with IODHE students, should become an imperative for institutions marketing their online programs to international audience [20, 36].

All of the strategies described here open the "residential" features of an institution and make significant progress toward a more global campus - one that is well on its way to accommodating IODHE coursework.

\section{TECHNOLOGY DISCOURSES FOR AN IODHE COURSE}

Technology replaces the brick and mortar infrastructure of a university's face-to-face curriculum and enables that curriculum to be replicated, adapted, challenged, or even re-invented for IODHE purposes. While providing access to quality education to IODHE students and mediating their course communication, technology adds a different sort of openness to a campus. But care must be taken to make sure that the virtual spaces are welcoming to IODHE students. Decisions made in this domain may determine whether persons from certain national, ethnic or economic groups can even participate in IODHE at all [37], but in addition to software, hardware and broadband questions, the work of Bruce King [38] emphasizes significant questions about how specific technology practices may support or complicate the delivery of instructional content. 


\section{A. Technology Issues for IODHE}

Students connecting across borders and cultures are quite vulnerable to the disparity in technology availability in different parts of the world. According to the Internet World Stats [39], the number of Internet users around the globe differs drastically: in North America almost $70 \%$ of population uses the Internet, but there are only 3.6\% of Africans, $10.7 \%$ of Asians and $10 \%$ of Middle Easterners who have such a privilege. Even Europe reaches only 38.9\%. Considering such statistics, there exists a high probability for mismatches in technology access and skills among students coming from different countries/cultures.

Belz [14], for example, reports on a US-German telecollaboration where differences in technological access and know-how caused unequal participation of two cultural groups. Liaw [15] observed that technological difficulties, such as system break-downs, exacerbated other complexities associated with cross-border/cross-culture communication. Howell et al. [19] describe a course in sub-Saharan Africa in which video, audio, and chats were attempted in the absence of adequate broadband support for the students. In all these cases, the differences in technology use and access created considerable frustration for everyone involved.

Software commonly used in the U.S. and some other countries such as Microsoft Power Point or PDF may not be available to students in less technologically developed countries. Nor should IODHE course developers automatically assume that students have broadband Internet connections or that the traffic is unlimited and cheap. Even downloading a text file in one of the latest additions of Microsoft Word could be problematic for some IODHE students. So providing files in alternate formats, e.g., converting latest version files to RTF or text-only can be crucial. Course developers can also reduce file sizes of images and audio/video materials, and provide good options for free or inexpensive software.

Cross-cultural complexities related to technology also exist on some quite subtle levels. A number of studies suggest that cultural background may influence the way users respond to web content and design features. Wurtz [40] found that websites developed for Japan, China and Korea made images more prominent thus providing an elaborate communication alternative to the text. In contrast, websites in Germany, Denmark, Finland used less animation and a more linear navigation. Evers [41] reported that subjects from English-speaking countries derived most of their understanding of the website from text rather than graphics, while Japanese students were more influenced by the graphics. Cultural variability was also prominent in studies by Marcus \& Gould [42] and Faiola \& Matei [43] who showed that web content is processed faster when created by designers from the user's culture. These preferences are significant for IODHE because web design features affect usability of web content and may increase or decrease the ability of students to access course content efficiently.

Composing and typing in chat environments offer little time to refer to dictionaries or to carefully formulate ideas [44]. Chinese students interviewed by Thomson \& Ku [45] found chat communication unpleasant and disorganized. Though synchronous chats are sometimes recommended as a community building tools (see, for example, [46]\}, IODHE course developers should beware of the pressure they can add to a student's participation. Dorazio, Hickok \& Thornton [47] report on an American-German project, where international teams were able to choose among a range of communicational technologies. They observed students using bulletin boards and online chats for communication and video podcasts for team camaraderie. Blogging, however, did not allow team members to have ongoing conversation threads and to group similar topics and made the German students uncomfortable about their command of English. 
Most online courses use an asynchronous written mode of communication, which has fewer visual and oral cues and makes conversations somewhat less personal. Warschauer [48] found that electronic discussions had fewer interactive features such as questioning, recasting, confirmation checks, and paraphrasing that are common in face-to-face interaction. Thus online conversations may loose coherence and immediacy, and may result in disengagement and lack of engaged interaction [49, 50]. Ware's study of telecollaboration between university students from Germany and the US revealed that though both groups of students posted frequently, they rarely engaged in interpersonal interaction (as indicated by response to direct questions, use of second-person pronouns, elaboration, etc) [49].

\section{B. Technology Practices that Offer Useful Virtual Spaces for IODHE Courses}

\section{The Basics}

Course developers are sometimes limited in their selection of learning management software because of the host institution's commitment to specific products. Many IODHE projects use open source software to supplement or replace a standard course management system. Dalsgaard [51] argues for using "educational social software", such as weblogs, wikis, RSS feeds, and social bookmarking, as alternatives that support a socially constructed e-learning and self-directed learning activities. These tools can also render the learning environment more sensitive to cultural and individual differences among learners.

No matter what technologies are employed, each IODHE course needs to be equipped with a "technology roadmap" that informs students of minimum hardware and software requirements prior to registration. This roadmap would also provide links to inexpensive downloadable programs and tutorials for those unfamiliar with the tools. Rochester Institute of Technology offers such a roadmap on customized course webpages [52]. The Online Student Orientation site at Old Dominion University also serves as a gateway to online courses and provides students with online tools to assess and upgrade their computer proficiency [53].

\section{Providing Technical Help}

In anticipation of technology mismatches across distance, course facilitators must consider how students will resolve technical difficulties. Having a help desk that answers questions by phone on a schedule tied to a local time zone and the host culture's holidays can limit IODHE student options for helpdesk service. Having a support team accessible 24/7 via telecommunication (both real-time and delayed) would be more desirable. Course developers and facilitators may also need to provide additional scaffolding related to technology skills. If a course assignment involves creation of electronic documents, instructors may need to provide alternative forms of knowledge/skills demonstration or offer technology tutorials for selfstudy. An excellent Student/Faculty HelpDesk system is a primary supplement to Pennsylvania State University's World Campus. HelpDesk technicians, accessible via email, real-time chat, or phone, are able to resolve $90 \%$ of reported problems within 15 minutes [54].

\section{Virtual (Computer-mediated) Discussions}

Electronic discussions, so popular among online educators in the U.S., should be adapted for IODHE so that they use the very simplest technology possible. Synchronous (real-time) modes of electronic communication need to account for worldwide time zones and allow for additional time for speakers with less fluency in the host campus language. Online chat systems can reduce response time to a minimum, but offer few visual oral cues to support understanding, and can increase anxiety. Some current technologies are emerging to take better advantage of synchronous exchanges and to incorporate oral messages and video, so the technology vocabulary of IODHE courses may eventually be able to counter 
these effects if there is adequate bandwidth on both sides of the distance.

And of course, some researchers have found computer-mediated communication to increase participation of students whose gender, cultural background, low self-assessment of language fluency or low status in groups hinder equal contribution to discussion in face-to-face formats [55]. Morse [56] reported that the ability to freely express their thoughts was rated the number one advantage of computer-mediated seminar discussion by non-native English speakers, and online students from China, interviewed by Thomson \& $\mathrm{Ku}$ [45], also felt more inclined to participate in electronic discussions. Thus cultural responses to technological decisions and practices must be accounted for by IODHE planners in ways that relate both to bandwidth and hardware as well as to teaching and learning choices.

\section{STUDENT AND FACULTY DISCOURSES AND LEARNING MODELS}

The opposite sides of our diagram (see Figure 1) represent the necessary dialogue between teaching and learning in IODHE coursework. The right side of the square represents both the students' various cultures as well as each individual's particular learning preferences. In the courses we describe here, there are likely to be cross cultural issues among the students. Thus the students must find ways to negotiate ways to comprehend their peers' responses to the course material in ways a mono-cultural classroom might not force them to explore. When IODHE students encounter dissimilar cultural assumptions about school or about how languages work, or how students ought to behave in school, these cultural distinctions need to become part of the course content and be perceived as acceptable and useful there.

Student discourse reflects students' educational values which are believed to be "shaped by (a) cultural norms, (b) the philosophy of learning to which we adhere, and (c) our personal preferences for learning" [5, p.117]. Previous educational experience influences an individual's expectations for a course and informs their learning strategies, communicational patterns, and beliefs about appropriate and fair assessment. Taken together, these factors can have a significant affect on a student's academic performance.

On the left side of figure 1, Faculty Discourses and Teaching Models drive the individual IODHE course via the selection and arrangement of course content and the enactment of the central educational model for the course. Just as students bring cultural "baggage" to the virtual environment, faculty do as well. We placed student and faculty domains opposite each other in the diagram to illustrate their reciprocal nature. Because of this interdependence, faculty and student IODHE discourses often cluster around similar issues that we will discuss in terms of their relationship to one another.

\section{A. IDOHE Student Discourses And Learning Models; Issues}

It is predicted that by 2025 there will be four times more prospective students interested in receiving higher education from non-local (out-of-native-country) educational institutions, and 70 percent of them will be Asians [57]. Though this prediction concerns all potential international students, one may expect that considerable number of these students will opt for online mode of education. Who are these international online students?

\section{Demographics}

In the U.S., online students are mostly fully employed professionals over 25 yeas old $[2,58]$ and they 
choose online programs as the most convenient way of obtaining education while balancing their professional and family responsibilities [56]. However, we should not assume that potential online students in other countries also fit this demographic group. In fact, undergraduate students from major cities working on their first degree are the most likely IODHE population in Asian-Pacific region [2]. This demographic may also be primary for other regions where online cross-border education may fill the niche left vacant by local educational institutions. Patton [59] further points out that distance education programs could attract international students who have to return home due to financial pressuresgenerally students with lower socio-economic status. Thus, demographic characteristics of students coming from different countries may differ on such dimensions as age, previous educational experience, motivation to study, and socio-economic status.

\section{Language Issues}

Since the U.S.A., Britain and Australia/New Zealand are three top leading producers of online education, many of the online courses discussed in the literature are monolingual with English being the dominant language. International online students are expected to bring to the course an adequate knowledge of English. However even when a satisfactory score on TOEFL (Test of English as a Foreign Language) is required to register for a course, many international students are unable to achieve parity in discussions and other written assignments with speakers whose first language is English. International students are also at risk of misinterpreting postings and assignments or of being misinterpreted by others thanks to misused vocabulary or grammar structures. There is also great potential for misreading communicative strategies such as turn taking, criticizing, apologizing, recasting, switching registers, and more. Idiomatic expressions, colloquialisms, regional or professional slang, references to local pop culture may also confuse second/foreign language speakers [81]. The intimidating nature of the process of written communication was well articulated by a Chinese student interviewed by Thomson \& Ku [45]:

I need to look words up in the dictionary occasionally. Sometimes I wonder what the teacher is going to think of my writing. They might think it’s too simplistic. I don't know whether they will use this simplicity to judge my writing or not.

The academic discourse of English speaking countries could also be an unfamiliar ground for many international students. The generally accepted theory of "contrastive rhetorics" pointed out by Kaplan [82] assumes that written discourse is structured and further interpreted in accordance with cultural thinking patterns embedded within a unique language system. In the online mode of education, where written discourse prevails and opportunities for negotiation of meaning can be limited, language background can complicate a students' performance in significant ways. Krampetz' study [83], which observed patterns of codes and code-switching among international students studying in a U.S. university, showed that international students struggle when trying to conform to requirements of formal academic writing and have to adjust their native ways of thinking, writing and "making meaning" to the U.S. models.

\section{Learning Styles: Cultural and Individual}

It is important for a discussion like this to avoid the black-and-white worldviews embedded in the scholarship that tends to create a bipolar view of cultural differences by constructing the east-west or north-south divides per the work of Edward Hall [60, 61] and Geert Hofstede [62, 63, 64]. In much of this work Western students are generally portrayed as verbal/analytic learners who are ready to critically analyze ideas, voice their own opinion, and challenge instructor' or peer's point of view, while Asian students are considered visual/holistic learners who perceive presented content and ideas as unquestionable and instructor's status indisputable and absolute [44, 45, 65, 66]. Cultural background is 
often made responsible for variations in learning styles observed from culture to culture (see, for example, [5, 67]). Asians are usually perceived as good test-takers, rote-learners and those who learn by observing and doing [16, 36, 45]; Europeans seem to prefer a self-discovery approach, whereas Americans are often taught using tell-and-test training materials [68].

Recent work by Agar [69] questions most generalizations about culture and suggests that intersections between individuals must account for the standpoint of individuals on either side of an encounter and that the concept of culture consists primarily of relationships rather than descriptive characteristics. An online course of the form we discuss here brings together 20-30 individuals that may not necessarily exhibit the typical (or stereotypical) behavior of their parent cultures. In fact some recent studies show that students coming from different cultural backgrounds may exhibit similar behavior patterns (see, for example, [70]), or conduct themselves in ways that do not align well with the assumed models of behavior for their national or ethnic heritage [71]. Nationally-driven constructs such as Hall's and Hofstede's may not meet "the challenge of dealing with cultural generalizations: in a nutshell, how to learn from the experience without falling into valueless stereotypes” [72, p.2]. Attention to personal idiolects and the regional dialects of individuals in an IODHE course might be a more productive and fair way of studying multicultural online communities. "As anything other than a generalized derivative, the individual disappears in an approach that uses the nation as a determinant of culture and thus of online behavior" [71]. But those individuals bring an OIDHE course both wealth and challenge as we shall discuss below.

\section{B. Faculty Discourses and Teaching Models: Issues}

Just as student discourses reflect students' educational values, faculty discourses manifest educational values of a faculty member's home culture and affect her or his philosophy of teaching and individual teaching style. The I-teach-how-I-was-taught model can be altered and modified with time and experience, but embedded cultural frames [73] determine the direction of these modifications and constrain faculty beliefs about what good teaching is. An Asian professor interviewed by Pan et al. [44, p. 328] recalls:

We were taught all the Confucian values. Like, we should respect our teacher. We should be humble. We should not speak too much. Just listen, don't talk too much. And don't try to raise too many questions.

The teaching models generally practiced in educational institutions that host IODHE programs must be flexible enough to address a great variety of students and faculty - including this Asian professor.

\section{Online Instructor Demographics}

Just as an institution may assume that their current curriculum can be converted to online instruction with relative ease, the identity and role of online faculty is often assumed rather than discussed. The literature is full of discussions of what students are like and what they may be apt to respond to in terms of teaching techniques and online pedagogies, but the diversity, attitudes and experience required of online instructors is unexplored in many discussions. The ubiquitous "online instructor" referred to in many studies however, may be a faculty member of any rank, an adjunct or lecturer, or in some cases a representative of a commercial firm contracted to produce and execute an online program. This outsourcing trend seems more likely if the online effort has been moved into marginal space in the institution such as continuing education, workforce instruction, or a specific online education unit.

Faculty often come to online teaching as self-selected early adopters and are most often fine teachers whose intellectual curiosity leads them to devote much time and energy to their projects. Adjuncts and part time instructors, a growing segment of many higher education systems, often see online instruction as a way to augment other jobs, to extend their qualifications for full time faulty status, or as a way to earn benefits ranging from tuition breaks to health insurance for their families. As with online students, there is 
considerable interest in the 24-7 and geographical convenience of online instruction. Given the reduction of distance through online coursework, instructors can be geographically as widely dispersed as the students are.

So if we presume students from all over the world in an IODHE course, we can also assume that the instructors can also be from all over the educational world. Of course, many institutions assume that their online efforts will be staffed by their current face to face faculty, but the commercial online education firms already recruit instructors from well beyond their immediate community and some of the oldest university-based online projects recruit for their programs worldwide (see especially Maryland, Penn State, and New Zealand Polytechnic). All this is to say that there's clearly not a "typical" online instructor or faculty member any more than there's a "typical" online student. So, what we say here must account for great variety in faculty discourse and teaching models unless an institution makes a concerted effort to align online teaching practices in the courses they offer. A primary issue, however, that informs much current faculty training for online instruction relates to teaching models that emphasize learner involvement and assume a teaching model in which the instructor's presence in the course is significant.

\section{Learner Involvement and Constructivism}

In the U.S., current online teaching theories tend to address not so much individual cognition but rather a context where students engage in "an act of enculturation... in mediated social context" [74]. This approach resists teacher-directed models of instruction in favor of learner-centered principles where the learner is given more responsibilities over the process of learning, and where she/he is encouraged to speak up, ask questions, doubt existing opinions and act as a co-constructor of knowledge along with her/his peers and the instructor. Moreover, numerous research studies conducted by U.S. scholars argue that learning effectiveness increases with frequent and quality interaction among and between online students and instructors (see short literature review by Swan [75]). Research by Jiang and Ting [76], for example, suggests that online instructors should place a considerable value on frequency and quality of postings in online discussions to promote student learning.

Thus most online courses that we are aware of make extensive use of threaded discussions and "conversation" tools embedded in modern learning management systems, such as Blackboard/WebCT, ANGEL or Moodle. In our experience 'quality' postings generally assume that students critically reflect on readings and postings of the instructor and peers, independently or in teams, find evidence in support of their own ideas, and express their thoughts in accordance with rules of formal academic writing.

Other constructivist strategies that appear in online courses involve project-based learning, interactive assignments, individual and group presentations, learning portfolios and the like. Such student-centered activities are also open-ended so as to encourage individual creativity and inspire good teamwork skills.

Students from cultures outside the U.S. may experience significant difficulties when placed in learning environment like these, so IODHE instructors may need to revise their instructional approaches when dealing with a course filled with students who may have learned primarily in teacher/test driven educational systems, or in European orals systems, or the Cambridge system with its weekly writing tutorials, or even in one-on-one tutorial environments. With such potential variety in the teaching histories present in an IODHE course, the importance of matching teacher discourses with student discourses should not be underestimated.

\section{Disciplinary Expectations}

Besides pedagogical philosophies and nationally accepted educational systems, a faculty member's own educational values may vary with his/her discipline. Becher [77] compared different academic disciplines to tribes that have their distinct cultures, while Bauer [78] showed that disciplines have different methods of generating knowledge, based on quite different epistemologies as well as specific teaching/learning 
preferences [79]. Moreover, research suggests that some faculty may doubt that their academic discipline is conducive to distance delivery [80]. These attitudes certainly influence the way such individuals approach online instruction.

\section{Faculty Preparation}

Some faculty may lack knowledge of how online technologies can be used in service of an academic discipline, but they may also have limited knowledge of pedagogy in general. Professionalization of preservice faculty in the cultures we know is still in its infancy. Doctoral programs across different disciplines may not train future university faculty in teaching at all; more often, university scholars are skilled in research methodologies and academic writing as practiced by their academic disciplines. Schools of Education train K-12 schoolteachers and rarely offer anything for future university professors. As a result, faculty members may lack pedagogical skills and reach out to their own experience as students for their only models of what instruction should be like. Years of teaching experience do help (though not for everyone) but in the complex context of cross-cultural online education, an IODHE student can be at much greater risk of failure with an underprepared instructor.

Thus, culturally loaded educational values, closely interwoven with individual preferences in learning, influence both faculty and student discourses in our diagram and require consideration when designing and facilitating an online course.

As this short description shows, IODHE students and faculty may have conflicting educational values. Cross-cultural literature touches these issues but it seems rarely anything is being done to accommodate needs of international students coming from diverse educational systems [84]. In online contexts, learning activities need to be matched to the particular students in a course not just the stereotypes of pseudomulticulturalism where nods to the global "norms" of national cultures are made topics of class discussions.

\section{Creating A Third Cultural Space for Learning and Teaching in IODHE Courses}

While institutional and technology strategies address IODHE issues on global level (unless, of course, the course has a self-paced automated structure) the quality of cross/inter-cultural experience one receives in a particular course depends on the work done by the instructor and the student inside the virtual classroom. We believe that this work requires imagining and building a safe 'third space' where students and instructor alike negotiate a new classroom environment where cultural assumptions about learning and teaching brought to the course can be honored, but where for the duration of the course, a new contingent cultural space is derived from the needs of everyone present [85]. Bretag [86] defines the third space as "a concept used to describe the possibility for a negotiated re-imagining of cultural identity [achieved by] constructing and re-constructing of identity, to the fluidity of space, to the space where identity is not fixed... [It] is where we negotiate identity and become neither this nor that but our own”. Bretag applied the concept of third space to teacher-student interaction and explored ways of changing hierarchical relationship between these "two very distinct 'cultural identities' predicated on unequal power relations within academia” [86].

We believe that all four domains in our diagram are responsible for building the safe learning/teaching environment needed for development of a successful IODHE course. But once certain conditions are set by the institution and the technologists, students and instructors must generate their own cultural space inside the virtual classroom; a successful third space effort primarily requires students and faculty to suspend some commitment to their previous schooling experience and look for new ways to relate to each other in this unfamiliar territory. 
A third space online classroom requires an environment of trust, respect and acknowledgement of multiple voices, appreciation of student goals, and faculty flexibility and reliability. In such a classroom, cultural and individual differences are not only acknowledged but also become a matter of exploration and pride. Differing cultures need to be provided with "mutual safe harbor" [44] where one culture does not dominate, and where those from underrepresented groups do not feel deficient. Students and teachers alike look for ways to avoid seeing cultural differences as 'deficits' and to discourage universalized metanarratives [6]. Negotiating the third space entails listening and giving all others the opportunity for selfexpression as well as a commitment from all parties to grasp this opportunity for generating new perspectives [87]. In the sections below, we'll explore the way a third space might function in an IODHE course--particularly in the areas of course content and course management.

\section{Course Content in a Third Space Course}

Teaching for an IODHE audience in a third space mode quite likely will require re-thinking and reworking the course content to make it relevant and comprehendible to students who do not share a common cultural heritage. The adjustment of the course content could necessitate the changes in the choice of texts, assignments, content language, and teacher expectations of how texts are interpreted and assignments are done. It also asks for reconsidering how new content is addressed.

\section{a. Diversification of Content Sources}

Culturally sensitive content would include cultural narratives and examples from international sources that represent the heritages of students in the course, but also represent international perspectives that might not be present. Textbooks from international authors, as well as collections of articles published worldwide, can be used to diversify content sources and illustrate ways to account for multiple perspectives. Non-textual content (images, sounds, and video) can be selected to avoid cultural bias and show appreciation of diverse cultural background of learners. Student examples and contributions to the course content would be essential for countering the tendency of the instructor's experience to become the "norm" for the course.

\section{b. Course Sssignments}

In a third space course, assignments and activities welcome expression of cultural identity and avoid onesided visions of the world. Efforts are made to create assignments appropriate for culturally diverse audience, similar to those found on the Rensselaer Polytechnic Institute (NY) website [88]. This collection of culturally-situated design tools illustrates how examples from non-dominant cultures can be used to teach mathematical concepts. One of these learning tools explains the concept of ratio though

Latino-Caribbean music and allows the learner to simulate traditional musical rhythms; another describes and illustrates transformational geometry and iteration using cornrow hairstyles traditional in African cultures. Designing such learning tools helped RPI students develop their programming and teaching skills at the same time it offered them a safe space to express their own cultural identity and learn respect for the customs of others.

Another good source for inspiration of culturally-sensitive activities is Wilderdom [89] This site explores the cultural bias in I.Q. tests, offers tests designed for cultural minorities (African-Americans, in this case), and provides discussion questions for promoting cultural pluralism. If such websites were more popular among online instructors, one of the authors of the present article could have avoided the frustration and resistance she experienced in an online ice-breaker activity which invited students to solve a set of visual puzzles entitled "I.Q. Test". Being a foreign language speaker unaccustomed to such puzzles, she felt this incident distanced her from the emerging online community, and diminished her self-confidence in the course. 


\section{c. Accessibility of Textbooks, Lectures, and Other Required Materials}

In IODHE, all materials related to the content of the course must be easily accessible worldwide. Amazon and other online stores popular in the USA do not deliver textbooks to all locations, and even when they do, the costs and shipping delays can be excessive. However, many online programs continue to require printed textbooks and place the responsibility for obtaining these books on students themselves (see, for example, [90]). A third space perspective reminds instructors to use primarily electronic content that can be accessible by everyone. University of Phoenix Online, for example, posts all lectures, questions and assignments online in text format which students can review off-line [91]. Keeping in mind the geographical spread of IODHE students, a third space IODHE instructor remembers to post detailed lectures online and provides electronic versions of additional readings selected to be copyright neutral. Moreover, now that many publishing houses have started offering books in digital formats, selecting electronic textbooks or publishing one's own electronic books can serve the varied needs of IODHE students.

Reusable digital learning objects may also be helpful. The MERLOT consortium [92] has assembled a large collection of peer-reviewed online learning objects coming from multicultural and multilingual sources and offers digital materials for both humanities and hard sciences. Indiana UniversityBloomington has created its own set of multimedia learning objects that can be redesigned and implemented in different online courses with little training and cost [93].

\section{d. Laboratory Work}

As many undergraduate and associate degrees students are required to take laboratory courses, lab partnerships can be arranged to serve third space goals of building trust and tolerance of others' views. Institutions and faculty look for ways to recreate laboratory experience either online or at home and shared among student teams. The University of Virginia has created a Virtual Science Lab which enables students of microelectronics to "climb inside objects, to see fields and forces, or to zoom in on things as tiny as atoms or electrons" from home [94]. Vanderbilt University has successfully experimented with off-the-shelf electronic laboratory simulation software [95], which eliminated the need to travel to physical laboratory settings. The Department of Biology at West Chester University has designed software for biology experiments [96]. Distance students of two chemistry professors at University of North Carolina, Wilmington and University of Colorado, Denver have turned students' home kitchens into chemistry labs [97]. Online courses offered at Minneapolis College of Art and Design re-recreate a studio-based model online [98].These projects and others illustrate ways that virtual and home labs and studios can allow online students to avoid trips to physical laboratories, but an IODHE third space instructor would take care that the "kitchens" being described and employed for such work were appropriate to the student cultures represented in the course..

\section{e. Using Local and Virtual Libraries}

Diversification of content sources can sometimes allow students to gain access to materials through local libraries. Additional learning materials required to complete assignments must be assessable on the WWW or via online libraries that provide direct access to its digital resources and offer free services in digitizing printed materials. Although many U.S. university libraries have started offering such services, apparently some of them have yet to recognize the need to minimize the size of digitized articles: one library, for example, delivers materials in PDF format where one article can exceeds $1 \mathrm{MB}$ and overwhelm a dial-up connection. A third space instructor learns whether this is a problem for her/his students and finds ways to work around such issues.

Some online libraries provide services in languages other than English. Long Beach City College library, 
for instance, assists its Spanish-speaking student population with information on their first language [99]. While such practices generally target Latino immigrants residing in the USA, library services in native languages of target international audience would be similarly helpful for the successful generation of a third space in IODHE courses.

Online interactive library services are currently available 24/7 to all patrons of libraries united through commercial reference management service software [100]. Maryland AskUsNow provides live online interactive services to Maryland students and residents belonging to over 30 university and public libraries [101]. While the chat format of such services could be problematic for some IODHE students, email reference services of highly qualified librarians could be of great help to many international distance learners.

\section{f. Language Issues}

As described above, IODHE learners may experience significant difficulties in a learning environment which 'speaks' a foreign language. Thus a third space course will find ways to use student languages wherever possible, and give special attention to the language used to describe concepts and communicate with international students. Researchers recommend avoiding complex syntax and idiomatic expressions, local humor, local insider examples, and culturally-bound allusions to ensure cultural neutrality and portability for a course and to minimize drop-out rates [5, 21, 81, 102].

Ideally, a third space IODHE course might operate in a multilingual mode with multilingual instructors, but more feasible solutions might include provision for using texts in other languages, translations and team teaching. This can be arranged by involvement of multilingual international graduate students, cooperation with foreign/second language instructors, and using transnational tandem teaching with involvement of local (international) educational institutions such as that reported in Howell et al. [19].

\section{g. Faculty/Student Expectations}

IODHE instructors and students alike must re-evaluate the process of content acquisition. Humanities courses with considerable interpretive variety (history, art, literature, for instance) need to allow for a variety of interpretations that could be brought to the table by individuals from different cultures. Without opportunities for students to identify and express their own predilections, there's little hope that employing stereotypes of their home cultures would be of much use in stimulating discussion or even authentic connections with the events, images or narratives introduced in the course. Misunderstandings of the content, misreading of assignment, as well as disappointment and dissatisfaction with the course, would be likely. Krampetz [83] reports on a student's frustration with the way the instructor treated the politics in the student's home country. While the instructor may have had her own vision of a topic, it was a mistake not to provide space for other points of view where students' inside knowledge of her/his culture is appreciated and respected. Such a space was created in the course of Taiwanese-US online collaboration, where electronic discussions were based on readings about students' own culture rather than the culture of their counterparts [15]. Students in this study felt that cross-cultural communication was rewarding and non-intimidating experience that supported the development of intercultural competence.

Some international students may require additional time for taking tests and provided extra scaffolding if web design features used in the course are believed to slow down content acquisition [43].

\section{Course Management and Housekeeping in a Third Space Course}


Course management strategies determine how a student interacts with the instructor, peers and course content, but a third space course, as noted above, may need a revised course management structure that builds trust, student ownership and a collaborative atmosphere. In this section we focus on some potentially effective strategies for third space approaches to IODHE course management.

\section{a. Participation and Interaction}

In the U.S., educational institutions and their faculty sometimes assume two opposing views over how dense should be social interaction among and between online students and instructors within the course. Currently prevailing is the belief that higher quantity of interaction supports student satisfaction and student learning [103]. Those who share this belief emphasize the importance of interaction and chose to require frequent participation in discussions and often include activities, such as learning journals, where students' interaction with the instructor becomes mandatory. Such are strategies encouraged to be practiced among faculty of State University of New York Learning Network (SLN) [104]. Others, however, choose to minimize mandatory interaction both among students and between a student and instructor. Some of Northern Virginia Community College's online courses have introduced a Tutorial Instructional Model where learner-instructor interaction is built into the course assignment submission and feedback process. Students in these courses are not obliged to interact with an instructor beyond this requirement, nor do they have to interact with peers [105]. Such approaches make a third space more difficult to establish, but selection of culturally appropriate materials and non-dominant examples and exercises can be helpful in these cases.

Both conversation rich and minimal interaction courses are listed in Sloan Consortium collection of effective online practices. The SUNY SLN strategy is based on socio-cognitive theories and supports a constructivist approach to learning, where active interaction is seen as an effective learning environment. While we value online discussions, especially for humanities courses, we should point out that for many IODHE students participation in discussions could be very stressful and problematic due to many reasons discussed above. Moreover, some instructors may also feel uncomfortable if the social density of the course they teach online exceeds the level of interaction they generally have in on-campus courses. The Northern Virginia Community College approach is first of all meant to accommodate those instructors who generally do not have discussions in on-campus courses, though voluntary participation in discussions can be beneficial for some international students as well.

Whichever strategies the course facilitator chooses to undertake, strategies related to participation and interaction would have to capitalize on such concepts as mutual respect, openness, readiness to speak up and listen, and, in some cases, appreciation of silence. Labour et al. [21] believe that online instructors should be "explicit and transparent about their tutoring techniques." In their e-workshop designed for online practitioners working in multicultural environment, they suggest that online instructors first raise their own self-awareness "by reflecting on how we assess ourselves and how we communicate with, and present ourselves to, others”. Openness and transparency, however, would have to be exhibited on both sides--the instructor's and students'. To generate a more thorough third space course, Thriving in Academe [106] recommends including students' and instructor's photos and requiring posting a short autobiographical sketch of each student, as well as administrating individual online conferences with each student via email or chat. Images and texts assist the online instructor in understanding the "codes of ethical values" [21], while helping both sides negotiate and establish third space compromises in a virtual classroom, thus diminishing the level of anxiety caused by confusing course expectations.

\section{b. Groups}

Team work, highly valued in the U.S. education, may also put an international student at a disadvantage. A third space classroom generally mixes together international and local students $[65,106])$. Such a 
recommendation is based on the assumption that both groups would benefit from the versatility of knowledge and skills brought in by team members. Indeed, such grouping is vital for international students when a course assignment is designed for local students by a local instructor. While collaborating with peers of the dominant culture, international students learn procedures for putting together multimedia presentations, making posters or role-playing, i.e. activities common for the host culture. In the situation where an international student is in the minority, she/he is expected to play in accordance with dominant culture rules and agree with the majority when negotiating for consensus. Third space instructors, however, work against seeing any student as an outsider and find ways to engage such students and honor their presence in the course.

In a third space IODHE course, indeed, team work needs to be designed to minimize the dominance of one culture. Of course working in virtual teams is more complicated than in face-to-face context, but achieving group cohesion, so important for successful team work, may be complex. Ishikawa [102] points out that "various cultures have different processes for making a decision in a group" and agrees with Dickson who argues that in virtual teams "group cohesion must take precedence over cultural differences" [107] as cited in [102]. Among recommended strategies, Dickson suggests that a multicultural team needs a member who would bridge cultural gaps through personal intervention. More feasible would probably be to design such team projects that would not require a final product to be aligned with one dominant culture. In addition, teams may be culturally homogeneous, but that they should also be exposed to other cultures through cross-team reviews/evaluations.

\section{c. Pacing}

Numerous studies suggest that such variables as workload and procrastination may increase drop-out rates among online students [108, 109, 110]. Finding reasonable course pacing becomes a matter of retaining students in class. Foreign language speakers with limited exposure to educational values of the host culture may find the amount of reading and assignments per course module daunting. While there is no formula that may calculate how much work and within what time frame would be reasonable, there is evidence to justify those instructors who practice flexibility with assignment deadlines. Such adjustments can be used as the subject matter for third space conversations about the tolerance for such shifts among class members.

Patton's study [59], which involved international and other non-traditional students studying in Australia, found that $89 \%$ of those who could not complete required assignments by regular deadline did complete the course when given the second chance. Not only does such a strategy allow students to spend more time on completing assignments, but it also accounts for cultural differences in perception of punctuality [102]. Moreover, some national course assessment systems (such as the Russian system) may diminish the importance of deadlines by having a single assessment point - the final exam (often oral). In the U.S., where tests and graded assignments are given throughout a semester and each assessment point is strictly scheduled, deadlines are supposed to be respected. To generate a third culture compromise, Ishikawa [102] recommends discussing the concept of "time" at the beginning of the course, while Patton [59] argues for flexible deadlines. Taken together, these strategies will make both a student and an instructor responsible for maximizing successful completion rates.

\section{d. Feedback}

Frequent and easily interpretable feedback is a key to establishing productive communication between the students and the instructor and can be an occasion for illustrating the third space nature of an IODHE course. The importance of feedback as a form of assessment and a means of work improvement is well documented in educational literature [111]. But the form of the feedback may constrain its effectiveness. Ciano [81] suggests considering the appropriateness of direct criticism when providing feedback. 
According to Ciano, American-style feedback is relatively direct and may offend some students. On the other hand, Elizarova [112], as well as our own experience, shows that many U.S. faculty members avoid the language that directly points out at flaws and wrap their critique in a form of suggestions, which some international students take only as advice one does not need to follow. Open discussion of this difference in the third space course can generate a resolution acceptable to all parties.

In third space IODHE, feedback also becomes a form of ongoing two-directional communication. It is not only an instructor who is to provide constructive, clear and timely feedback on students' work, but also students themselves who are to express their thoughts and feelings on their learning experience. Feedback from students could be obtained through self-reflection journals, bulletin boards, discussion forums, weblogs and other communication channels. These public and private spaces must be designed as safe environments for sharing one's concerns and anxieties, as channels for discussing course issues, and even as a place to share intimate information. Bretag [86] found that private email communication with her ESL students initiated personal friendship and indicated "movement towards a transcendent third space relationship." Appreciation of silence, however, assumes that the instructor makes communication voluntary and/or creates low anxiety environment that supports third space ideas.

\section{e. Assessment}

Considering the diversity of assessment systems worldwide, course instructors may have to reconsider their typical requirements that reflect one dominant culture. For example, requirements for the quality and quantity of online discussions in courses designed in the U.S. often reflect only "western" educational values that encourage eloquence, wordiness, originality, grammatical and spelling accuracy, frequency, and so on. Courses opened to international audience would need to consider the linguistic abilities of foreign language speakers and their readiness to speak up, critically reflect on readings, and use rules of rhetoric appropriate for academic writing. Depending on the course discipline and audience, the strategies for dealing with cultural mismatch in course assessments may include acceptance of language imperfections, lurking [19], mimicking dominant discourse [83], as well as language-switching tolerance [21]. Adjustment of assessment criteria may have to involve changes in grading scales and other forms of feedback.

\section{f. Grading}

Grading scales and numerical grading itself may be foreign to some IODHE students. Lamontagne found that to Arabic students, "the tradition of assigning a numeric value to intelligence, and to differentiate students based on this value has little inherent meaning" [113, p.10]. Calculation of points, designation of percentages earned for each assignment or the idea of bonus points may not be well comprehended by multicultural audiences. Assessment criteria meant to ensure fairness and objectivity may in fact turn against some IODHE students. Apparently, the grading system must be 1) well articulated and 2) flexible. It could be suggested that the instructor provides a general frame for assessment criteria in the form of rubrics, which are further developed and detailed by students themselves. As numerical grading (or assigning letter grades) may not be a part of some students' schemata for "how school work is assessed," the instructor may need to consider pass/fail forms of evaluation or other more descriptive forms of feedback.

\section{GENERAL RECOMMENDATIONS}

IODHE providers will inevitably face many of the issues related to four discourses - institutional, technology, students and faculty, and they will need to reconsider their institutional policies to accommodate needs of IODHE students and faculty. The list below offers recommendations that we believe to be particularly helpful to institutions participating or planning to participate in cross- 
border/cross-culture online education.

\section{1. . Design Courses that Target Specific International Audiences}

Tailoring online courses to specific audience may help avoid at least some issues associated with crossborder/cross-culture education. Localizing specific courses for relatively homogeneous audiences or internationalizing courses in the same way universal design drives accessibility for special needs. Such courses should necessarily possess a low level of cultural contextualization [114] or high degree of cultural portability [115] to ensure their applicability in diverse cultural settings.

\section{Provide Advance and Detailed Information}

The gap existing between IODHE students' preparedness and faculty expectations needs to be filled in by a clear and detailed course syllabus easily available to prospective students before they sign up for the course.

\section{Offer Proactive Student Support}

To help students to make the right choice of the course or academic program and get prepared, institutions need to provide students with adequate advising and support prior to program or course registration. This support may come in the form of skill surveys, pre-assessment tests, tutorials, or pre-requisite courses as well as virtual advising and mentoring.

\section{Provide Ongoing Student Support in a Variety of Communication Media}

While 24/7 ongoing academic and technical support may not be feasible, institutions and individual faculty members need to make available prompt feedback in a variety of communicational media. Online library services with expertise in foreign languages are useful.

\section{Train and Support your Faculty}

Ongoing support and training for faculty should include onsite and online professional development for new online faculty and continuing professional support to returning faculty. Partnerships and team teaching with overseas experts should be encouraged.

\section{Re-evaluate Policies on International Education}

Successful IODHE practices require re-evaluation of existing departmental and institutional policies as well as national policies of the host culture. Such re-evaluation should take particular note of policies related to student and faculty recruitment, enrollment, immigration, fees, assessment, and residency requirements.

\section{CONCLUSION}

In this paper we have shown how International Online Distance Higher Education is complicated by the discourses of institutions, technology, instructors and students, and we have explored ways that a third space approach to a IODHE course may require a different approach in all these areas to insure student success. The pathway to productive programs and student success is still evolving, so our research reviewed assumptions of virtual classroom technologies worldwide, and teaching and learning strategies that assume a third space approach.

As distance education incorporates new technologies such as mobile devices and ever more complex 
multimedia tools, individuals and institutions involved in IODHE may continue to experience many old problems related to adequate academic and technology support unless a broader view of IODHE prevails. We acknowledge the pioneering projects represented in this review as evidence that broader view is possible.

\section{ABOUT THE AUTHORS}

Gulnara Sadykova is a doctoral student in the Department of Educational Theory and Practice, University at Albany. She is also an assistant professor at the Department of Romance and Germanic Philology, Kazan State University, Russia. She holds an advanced degree in Comparative Linguistics from the same university. Her research interests include cross-culture/cross-border distance education, technology-assisted language teaching/learning, and online learning.

Jennie Dautermann is Teaching Learning and Technology Program Manager at the SUNY Center for Professional Development in Syracuse. She is a former faculty member in the Technical Communication program in English at Miami University, Oxford, Ohio where she also served as Director of College Composition and Associate Dean of Arts and Science. She holds a PhD in Rhetoric and Composition with a specialty in Technical Communication from Purdue University. Her research interests and publications address teaching with technology, writing in non-academic and second language settings, and qualitative research methods.

\section{REFERENCES}

1. Open Doors 2005: International Students in the United States. Press release, 2005. http://opendoors.iienetwork.org/?p=69736.

2. Marginson, S. Don't leave me hanging on the Anglophone: The potential for online distance higher education in the Asian-Pacific Region. Higher Education Quarterly 58(2/3): 74-113, 2004.

3. van der Wender, M. The Role of US Higher Education in the Global E-learning Market. Research and Occasional Paper Series CSHE.1.02, Center for the Study of Higher Education, University of California, Berkeley, (Berkeley: CSHE), 2002. http://cshe.berkeley.edu/publications/docs /ROP.WendePaper1.02.pdf.

4. McIsaac, M. S. Online Learning from an International Perspective. Educational Media International 39(1): 17-21, 2002.

5. Bentley, J. P. H, M. V.Tinney \&B. H. Chia. Intercultural Internet-based Learning: Know your audience and what it values. Educational Technology Research and Development 53(2): 117-127, 2005.

6. Lauzon, A. C. Situating cognition and crossing borders: resisting the hegemony of mediated education. British Journal of Educational Technology 30(3): 261-276, 1999.

7. Darrup-Boychuck, C. Harnessing the power of the Internet for international student recruitment. The Technology Source: January/February 2002. http://ts.mivu.org/default.asp?show=article\&id=1034.

8. Sedgwick, R. Online education may impact foreign recruitment. World Education News \& Reviews 12(2): March/April 1999. http://www.wes.org/ewenr/99mar/research.htm.

9. Harley, D., S. Lawrence, S. Ouyang \& J. L. White. (Eds). University Teaching as E-business? Research and Policy Agendas. Selected Conference Proceedings, University of California, Berkeley, October 26-27, 2001.

10. Australia's Competitors in International Education: July 2005 Update. Australian Educational International: July 2005. http://aei.dest.gov.au/AEI/PublicationsAndResearch/Publications /CompAnalysisJuly05_pdf. 
11. Adam, S. Transnational Education Project Report and Recommendations. 2001. http://eees.universia.es/documentos/otros/complementarios/ transnational-education-project.pdf.

12. Knipe, R. Personal communication. Genesee Community College, Batavia, NY, 2007.

13. Sedgwick, R. Diploma mills go digital. World Education News \& Reviews 13(4): 2000. http://www.wes.org/ewenr/00july/feature.htm.

14. Belz, J. A. Social dimensions of telecollaborative foreign language study. Language Learning \& Technology 6(1): 66-81, 2002.

15. Liaw, M. E-learning and the development of intercultural competence. Language Learning \& Technology 10(3): 49-64, 2006.

16. Cole, J. \& B. Robertson. Using market segmentation to develop a large section, web-enhanced survey course. Innovate 2(4): 2006. http://www.innovateonline.info/index.php?view=article\&id=61.

17. Collis, B. Designing for differences: cultural issues in the design of WWW-based course-support sites. British Journal of Educational Technology 30(3): 201-215, 1999.

18. Al-Jarf, R. S. Cross-cultural Communication: Saudi, Ukrainian and Russian Students Online. ERIC Document Reproduction Service No. ED489964, 2004.

19. Howell, S., M. C. Harris, S. A. Wilkinson, K. Zuluaga, \& P. Voutier. Teaching mixed-mode: A case study in remote delivery of computer science in Africa. International Media Educational 41(4): 297-306, 2004.

20. Wiesenberg, F. \& E. Stacey. Reflections on teaching and learning online: Quality program design, delivery and support issues from a cross-global perspective. Distance Education 26(3): 385-404, 2005.

21. Labour, M., C. Juwah, N. White \& S. Tolley. Online Tutoring e-Book: Culture and Ethics: Facilitating Online Learning, 2000. http://otis.scotcit.ac.uk/onlinebook/otisT6p.htm.

22. Branden, J. V. \& J. Lambert. Cultural issues related to transnational Open and Distance Learning in universities: a European problem? British Journal of Educational Technology 30(3): 251-260, 1999.

23. Distance Degree Programs: Course Basics. Washington State University website. http://www.distance.wsu.edu/courses/basics.asp.

24. Adkins, M. Practice: Syllabus display and time on task. Sloan-C Effective Practices, 2002. http://www.sloan-c.org/node/241.

25. Oaks, M. Practice: Introduction to course and professor welcomes learners. Sloan-C Effective Practices, 2002. http://www.sloan-c.org/node/242.

26. Jiang, M. Practice: Strategies for mentoring online adult learners in a competency-based degree program. Sloan-C Effective Practices, 2002. http://www.sloan-c.org/node/248.

27. Cochrane, P. Practice: Proactive academic advising for distance students. Sloan-C Effective Practices, 2004. http://www.sloan-c.org/node/381.

28. Sax, B. Practice: Wizards: Student tutors help peers learn. Sloan-C Effective Practices, 2002 http://www.sloan-c.org/node/240.

29. Benke, M. Practice: Capella University’s online writing support center. Sloan-C Effective Practices, 2003. http://www.sloan-c.org/node/389.

30. Clerkin M. J. Practice: A comprehensive plan for preparing online students. Sloan-C Effective Practices, 2004. http://www.sloan-c.org/node/393.

31. DiPaolo, A. Practice: Courselets designed for custom tutorials. Sloan-C Effective Practices, 2002. http://www.sloan-c.org/node/239.

32. Schechner, K. Practice: Creation of focused educational planning environment meets army student needs. Sloan-C Effective Practices, 2004. http://www.sloan-c.org/node/234.

33. Maryland Faculty Online. http://www.mdfaconline.org/index.html.

34. Puzziferro, M. Practice: Supporting online adjunct faculty: A virtual mentoring program. Sloan-C Effective Practices, 2004. http://www.sloan-c.org/node/365.

35. Pickett, A. Practice: Faculty development process. Sloan-C Effective Practices, 2002. http://www.sloan-c.org/node/347. 
36. McNaught, C. Development and support for the global e-teacher. Global Educator 2003. http://www.globaled.com/articles.html.

37. Kurt, L. Internationalization of higher education: OECD perspectives. In Harley, D., Lawrence, S., Ouyang, S., \& White, J.L. (Eds). University Teaching as E-business? Research and Policy Agendas. Selected Conference Proceedings, University of California, Berkeley (October 26-27, 2001), 2002. http://cshe.berkeley.edu/publications/publications.php?id=38.

38. King, B. Refocusing quality: moving towards 'extreme evaluation. In Proceedings of the 11th Cambridge International Conference on Open and Distance Learning: 96-100, 2005. http://www2.open.ac.uk/r06/conference/papers2005.pdf.

39. Internet World Stats: Usage and Population Statistics, 2007. http://www.internetworldstats.com/stats.htm.

40. Würtz, E. A cross-cultural analysis of websites from high-context cultures and low-context cultures. Journal of Computer-Mediated Communication 11(1): article 13, 2005. http://jcmc.indiana.edu/vol11/issue1/wuertz.html.

41. Evers, V. Cross-cultural understanding of graphical elements on the DirectED website. In Smith, A (Ed.), Proceedings of Annual Workshop on Cultural Issues on HCI (5 December 2001), Putteridge Bury, University of Luton, 2001.

42. Marcus, A. \& E. W. Gould. Cultural dimensions and global web user-interface design: What? So What? Now What? In Proceedings of the 6th Conference on Human Factors and the Web. Austin, Texas, 2000. http://www.amanda.com/resources/hfweb2000/AMA_CultDim.pdf.

43. Faiola, A., \& S. A. Matei. Cultural cognitive style and web design: Beyond a behavioral inquiry into computer-mediated communication. Journal of Computer-Mediated Communication 11(1): article 18, 2005. http://jcmc.indiana.edu/vol11/issue1/faiola.html.

44. Pan, C.-C, M.-H. Tsai, P. -Y. Tsai, Y. Tao \& R. Cornell. Technology's impact: Symbiotic or asymbiotic impact on differing cultures? Educational Media International 40(3/4): 319-330, 2003.

45. Thompson, L. \& H.-Y. Ku,. Chinese graduate students' experiences and attitudes towards online learning. Educational Media International 42(1): 33-47, 2005.

46. Shield, P., B. Atweh \& P. Singh. Utilising synchronous web-mediated communications as a booster to sense of community in a hybrid on-campus/off-campus teaching and learning environment. In ASCILITE Conference Proceedings, December 4-7, 2005, Brisbane, Australia. http://www.ascilite.org.au/conferences/brisbane05/blogs/proceedings/70_Shield.pdf.

47. Dorazio, P., C. Hickok \& S. Thornton. Modeling the Global Workplace Using Emerging Technologies. Paper presented at CIT Conference, May 2007.

48. Warschauer, M. Comparing face-to-face and electronic discussion in the second language classroom. CALICO Journal 11(2/3): 7-26, 1996.

49. Ware, P. D. From Involvement to Engagement in Online Communication: Promoting Intercultural Competence in Foreign language Education. Unpublished doctoral dissertation, University of California, Berkeley, 2003.

50. Kern, R., P. Ware \& M. Warschauer. Crossing frontiers: New directions in online pedagogy and research. Annual Review of Applied Linguistics 24: 243-260, 2004.

51. Dalsgaard, C. Social software: E-learning beyond learning management systems. European Journal of Open, Distance, and E-Learning: 2, 2006. http://www.eurodl.org/materials/contrib/2006 /Christian_Dalsgaard.htm.

52. Vignare, K. Practice: Getting started with Customized Online Course Pages. Sloan-C Effective Practices, 2002. http://www.sloan-c.org/node/387.

53. Robinson, M. Practice: Distance learning online student orientation website. Sloan-C Effective Practices, 2005. http://www.sloan-c.org/node/377.

54. Thomson, M. Practice: Student/faculty help desk. Sloan-C Effective Practices, 2003. http://www.sloan-c.org/node/385.

55. Bump, J. Radical Changes in Class Discussion Using Networked Computers. Computers and the Humanities 24: 49-65, 1990. 
56. Morse, K. Does One Size Fit All? Exploring Asynchronous Learning in a Multicultural Environment. Journal of Asynchronous Learning Networks 7(1): $2003 . \quad$ http://www.sloanconsortium .org/publications/jaln/v7n1/v7n1 morse.asp.

57. Bohm, A., D. Davis, D. Meares \& D. Pearce. Global Student Mobility 2025: Forecasts of the Global Demand for International Higher Education. Canberra, IDP Education, Australia, 2002. http://www.idp.com/16aiecpapers/program/thursday/marketing2/ Bohm_2025Media_p.pdf.

58. The 2005 National Online Learners Priorities Report. Noel-Levitz Inc., 2005. https://www.noellevitz.com/Papers+and+Research/Research/ResearchLibrary/2005+National+Satisfa ction+Report.htm.

59. Patton, M. A. The importance of being flexible with assignment deadlines. Higher Education in Europe XXV(3): 2000.

60. Hall, E. T. Beyond Culture. New York: Doubleday, 1976.

61. Hall, E. \& M. Hall. Understanding Cultural Differences. Yarmouth, ME: Intercultural Press, 1990.

62. Hofstede, G. Cultural differences in teaching and learning. International Journal of Intercultural Relations 10: 301-320, 1986.

63. Hofstede, G. Cultures and Organizations: Software of the Mind: Intercultural Cooperation and its Importance for Survival. New York: McGraw Hill, 1991.

64. Hofstede, G. A case for comparing apples and oranges. International Journal of Comparative Sociology 39(1): 16-31, 1998.

65. Biesenbach-Lucas, S. Asynchronous discussion groups in teacher training classes: Perception of native and non-native students. Journal of Asynchronous Learning 7(3): September, 2003. http://www.sloanconsortium.org/publications/jaln/v7n2/index.asp.

66. Lim, D. H. Cross cultural differences in online learning motivation. Educational Media International 41(2): 163-173, 2004.

67. Grushevitckaja, T. G., V. D. Popkov \& A. P. Sadokhin. Osnovy Mezhkulturnoj Kommunikatcii: Uchebnik Dlya Vuzov. Moscow: YUNITI-DANA, 2003.

68. Shadbolt, D. On-line training for multilingual markets: Localization is key to successful e-learning systems in Europe. Multilingual Computing \& Technology 13: 51-55, 2002.

69. Agar, M. Culture: Can you take it anywhere? Invited lecture presented at the Gevirtz Graduate School of Education, University of California at Santa Barbara. International Journal of Qualitative Methods 5(2): article XX, 2006. http://www.ualberta.ca/ iiqm/backissues/5_2/pdf/agar.pdf.

70. Samarawickrema, R. G. Determinants of student readiness for flexible learning: Some preliminary findings. Distance Education 26(1): 49-66, 2005.

71. Hewling, A. Culture in the online class: Using message analysis to look beyond nationality-based frames of reference. Journal of Computer-Mediated Communication 11(1): article 16, 2005. http://jcmc.indiana.edu/vol11/issue1/hewling.html.

72. Yeager, D. \& J. Sivell. ESL Teachers' Perceptions of the Cultural Variables that Impact on Teaching and Learning in the SL Classroom. Paper presented at the Annual meeting of the Canadian Association of Applied Linguistics (Quebec City, Quebec, Canada, May 2001). ERIC Document Reproduction Service No. ED 475738, 2001.

73. van Dejk, T. A. Jazyk, Poznanie, Kommunikatcija. Moscow, 1989.

74. Gallini, J. K. \& D. Barron. Participants' perception of web-infused environments: A survey of teaching beliefs, learning approaches, and communication. Journal of Research on Technology in Education 34(2): 139-155, 2001-2002.

75. Swan, K. Relationships between Interactions and Learning in Online Environments. The Sloan Consortium, 2003. http://www.sloanconsortium.org/publications/books/pdf/interactions.pdf.

76. Jiang, M. \& E. Ting. A study of factors influencing students' perceived learning in a web-based course environment. International Journal of Educational Telecommunications 6(4): 317-338, 2000.

77. Becher, T. Academic Tribes and Territories: Intellectual Enquiry and the Cultures of Disciplines. London: Open University Press, 1989. 
78. Bauer, H. Barriers against Interdisciplinarity: Implications for studies of science, technology and society. Science, Technology and Human Values 15(1): 105-119, 1990.

79. Bradbeer, J. Barriers to Interdisciplinarity: Disciplinary Discourses and Student Learning. Journal of Geography in Higher Education 23(3): 381-396, 1999.

80. O’Quinn, L. \& M. Corry. Factors that deter faculty from participating in distance education. Online Journal of Distance Learning Administration 5(4): 2002. http://www.westga.edu/ distance lojdla/winter54/quinn54.html.

81. Ciano, L. Special Considerations When Teaching Non-native English in an Online Environment. Paper presented at the Eighth Annual Teaching in the Community Colleges Online Conference "The Student Experience in Online and Hybrid Courses" (April 22-24, 2003). http://makahiki.kcc.hawaii.edu/tcc/2003/conference/presentations/ciano.html.

82. Kaplan, R. Cultural thought patterns in inter-cultural education. Language Learning 16: 1-20, 1966.

83. Krampetz, E. M. Writing across Cultures and Contexts: International Students in the Stanford Study of Writing. A Monograph in partial fulfillment of the requirements for the degree of Master of Arts. Stanford University, 2005.

84. International Students Need Help Online. Interview with representatives of City University vocational school, Bellevue, Washington. Magna, October 1, 2005. http://www.magnapubs.com/issues/magnapubs_der/9_19/news/597972-1.html.

85. Bhabha, H. K. Location of Culture. London and New York: Routledge, 1994.

86. Bretag, T. Developing 'third space' interculturality using computer-mediated communication. Journal of Computer-Mediated Communication 11(4): article 5, $2006 . \quad$ http://jcmc.indiana.edu /vol11/issue4/bretag.html.

87. Hannula, M. Third space: Merry-go-round of opportunity. Kiasma Magazine 12(1): 2001. http://www.kiasma.fi/www/viewresource.php?lang=en\&id=3LoHIn6PkQfTgv09.

88. Culturally Situated Design Tools: Teaching Math through Culture. Rensselaer Polytechnic Institute website. http://www.rpi.edu/ eglash/csdt.html.

89. Multicultural, Cross-cultural \& Intercultural Games \& Activities. Wilderdom Website. http://wilderdom.com/games/MulticulturalExperientialActivities.html.

90. Distance Education. University of Wisconsin - Platteville. Website. http://www.uwplatt.edu /disted/degrees/textbook.html.

91. How It Works. University of Phoenix Online Website. http://www.uopxworld.com/howitworks.asp.

92. MERLOT Website. http://www.merlot.org/merlot/index.htm.

93. Dunning, J. Practice: Repurposeable learning objects: the TALON learning object system. Sloan-C Effective Practices, 2003. http://www.sloan-c.org/node/230.

94. Virtual Science Lab. The University of Virginia Website. http://www.virlab.virginia .edu/VL/home.htm.

95. Campbell, O. Practice: Cost-effective distributed learning with electronics labs. Sloan-C Effective Practices, 2003. http://www.sloan-c.org/node/263.

96. Bishop, T. Practice: Virtual biology laboratory. Sloan-C Effective Practices, 2003. http://www.sloanC.org/node/1097.

97. Carnevale, D. Baking Soda, Vinegar, and Measuring Cups Become Lab Materials for Online Chemistry Course. Chronicle of Higher Education November 12, 2002. http://chronicle.com/free/2002/11/2002111201t.htm.

98. Alm, R. Practice: Re-creating the studio-based model online for art and design education. Sloan- $C$ Effective Practices, 2003. http://www.sloan-c.org/node/333.

99. Student Services. Long Beach City College Library Website. http://success.lbcc.edu/resourcesspanish.htm.

100. QuestionPoint; 24/7 Reference Services. http://questionpoint.org/.

101. Sener, J. Practice; live online interactive library services-statewide. Sloan-C Effective Practices, 2004. http://www.sloan-c.org/node/282. 
102. Ishikawa, L. Intercultural Aspects of CMC. Lecture notes for DMST 4503 Seminar in Internet Communication. University of Denver, 2002. http://www.du.edu/ jrutenbe/4503/intercultural.htm.

103. Shea, P., K. Swan, E. Fredericksen, \& A. Pickett. Student Satisfaction and Reported Learning in the SUNY Learning Network: Interaction and Beyond. Online Education v.3. Proceedings of the 2001 Summer Workshop on Asynchronous Learning Networks. Needham, MA: Sloan Center for Online Education, 2002.

104. Sener, J. Practice: Student satisfaction and reported learning: Interaction, learning community formation, and beyond. Sloan-C Effective Practices, 2002. http://www.sloan-c.org/node/397.

105. Hatheway, B. Practice: Tutorial instructional model. Sloan-C Effective Practices, 2002. http://www.sloan-c.org/node/223.

106. Thriving in Academe: The changing world of international students. NEA Advocate Online, December 2006.

107. Dickson, C. C. Intercultural Communication in Virtual Teams: Case Study of the Japan-America Student Conference. A Thesis Outline, 1999.

108. Hartman, J. A. ATFY-R: Psychometric Properties and Productive Value for Academic Performance in Online Learning. Unpublished Doctoral Dissertation. The University of Alabama, Tuscaloosa, AL, 2001.

109. Nash, R. D. Course completion rates among distance learners: Identifying possible methods to improve retention. Online Journal of Distance Learning Administration 8(4): 2005.

110. Richards, C. N. \& D. R. Ridley. Factors affecting college students' persistence in on-line computer-managed instruction. College Student Journal 31(4): 1997.

111. Palloff, R. M. \& K. Pratt. Collaborating Online: Learning Together in Community. JosseyBass, San Francisco, CA, 2005.

112. Elizarova, G. V. Kultura i Obuchenie Inostrannym Yazykam. St. Petersburg: KARO, 2005.

113. Lamontagne, M. Communities of practice in an Arabic culture: Wegner's model and the United Arab Emirates implications for online learning. Turkish Online Journal of Distance Education 6(3): article 1, July 2005.

114. McLoughlin, C. Culturally inclusive learning on the web. In K. Martin, N. Stanley and N. Davison (Eds.), Teaching in the Disciplines/Learning in Context. Proceedings of the 8th Annual Teaching: 272-277, 1999. http://lsn.curtin.edu.au/tlf/tlf1999/mcloughlin.html.

115. McBrien, K. Developing localization friendly e-learning. Learning Circuits May 2005. http://www.learningcircuits.org/2005/may2005/mcbrien.htm. 